\title{
What Is Known about Secondary Grades Mathematical Modelling --A Review
}

\author{
Micah Stohlmann ${ }^{1}$, Lina DeVaul ${ }^{1}$, Charlie Allen ${ }^{1}$, Amy Adkins ${ }^{1}$, Taro Ito ${ }^{1}$, Dawn Lockett ${ }^{1} \&$ Nick Wong $^{1}$ \\ ${ }^{1}$ Department of Teaching and Learning, University of Nevada, Las Vegas, Las Vegas, Nevada \\ Correspondence: Micah Stohlmann, Department of Teaching and Learning, University of Nevada, Las Vegas, Las \\ Vegas, Nevada, 89154, USA. E-mail: micah.stohlmann@unlv.edu
}

Received: June 28, 2016 Accepted: July 21, 2016 Online Published: September 14, 2016

doi:10.5539/jmr.v8n5p12 URL: http://dx.doi.org/10.5539/jmr.v8n5p12

\begin{abstract}
Mathematical modelling is garnering more attention and focus at the secondary level in many different countries because of the knowledge and skills that students can develop from this approach. This paper serves to summarize what is it known about secondary mathematical modelling to guide future research. A targeted and general literature search was conducted and studies were summarized based on four categories: assessment data collected, unit of analysis studied, population, and effectiveness. It was found that there were five main units of analysis into which the studies could be categorized: modelling process/sub-activities, modelling competencies/ability, blockages/difficulties during the modelling process, students' beliefs, and construction of knowledge. The main findings from each of these units of analysis is discussed along with future research that is needed.
\end{abstract}

Keywords: literature review, mathematical modeling, modelling competencies, modelling process, secondary school

\section{Introduction}

Mathematical Modelling is gaining increased interest in countries' mathematics education standards documents (e.g. Ärlebäck, 2009a; Common Core State Standards Initiative, 2010). In Sweden, mathematical modelling is one of seven mathematical abilities to develop in students. Germany includes mathematical modelling as one of six compulsory competencies (Blum \& Borromeo Ferri, 2009). In the United States, mathematical modelling is one of eight Standards for Mathematical Practice. Australia has mathematical modelling as part of the concepts and techniques that students should know in the National Mathematics Curriculum (Australian Curriculum, Assessment and Reporting Authority, 2015). Mathematical modelling activities can develop in students needed mathematics content knowledge and life skills for them to be successful in the $21^{\text {st }}$ century (Stohlmann, 2013). However, there is no one agreed upon conceptualization of mathematical modelling (Frejd, 2013) and there are many versions of the mathematical modelling cycle (e.g. Blum \& Leib, 2007; Kaiser, 1995; Lesh \& Doerr, 2003a). In order to guide the research and teaching of mathematical modelling, essential elements of mathematical modelling should be detailed and an analysis of the current literature on middle and high school mathematical modelling is needed.

Our definition of mathematical modelling is an iterative process that involves open-ended, real world, practical problems that students make sense of with mathematics using assumptions, approximations, and multiple representations. Other knowledge besides mathematics can be used as well. Mathematical modelling curricula should have multiple acceptable models that can be developed (Stohlmann \& Albarracin, 2016). Curriculum is explicitly tied to mathematical modelling research as studies make use of modelling curricula.

Kaiser (2011) noted key questions for the topic of applications and modelling: "What are research deficits? Can we identify them? What kind of empirical research is necessary?" (p. 926). We present a literature review that details the units of analysis, assessment data collected, population, and the effectiveness of the mathematical modelling activities at the middle and high school level (ages 11-18). This analysis is discussed in the context of what future research is needed in mathematical modelling. First we present a framework of the essential elements of mathematical modelling.

\section{Essential Elements of Mathematical Modelling}

While there are different mathematical modelling cycles, there are key elements that should be included. Lesh and Doerr (2003a) have a modelling cycle that highlights three of our essential elements of mathematical modelling (Figure 1). Mathematical modelling must start with a real world problem. Students make sense of it with mathematics involving assumptions and approximations, often called mathematizing, and then must ensure that the mathematics is accurate and makes sense in the realistic situation. 


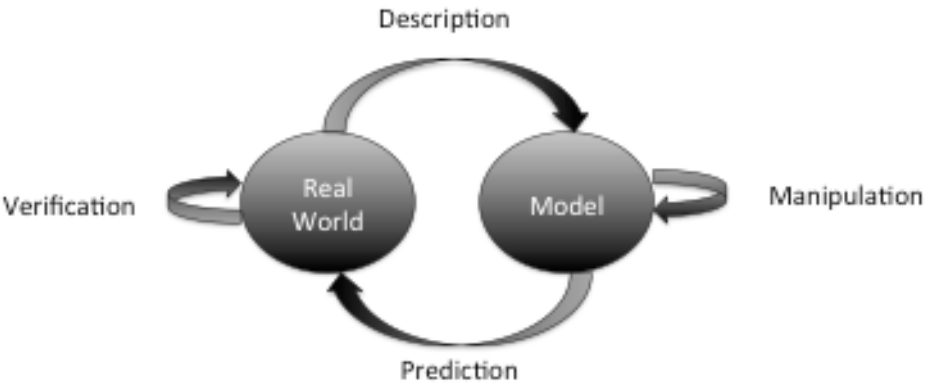

Figure 1. Lesh and Doerr's (2003a) modeling cycle

Another essential element is the inclusion of key questions that stem from the real world problem. A key question can guide the solution and work of a mathematical modelling activity. The key question provides direction for the problem to be solved. An example of a key question is, how big is someone based on his or her footprint and stride length? (Lesh \& Doerr, 2003a). A key question can serve to focus work and is often the way that people approach problems in their jobs.

Perrenet and Zwaneveld's (2012) cycle has a similar structure to Lesh and Doerr's (2003a) cycle but provides more detail and highlights three more essential elements of mathematical modelling. Both clear verbal and written communication is paramount while students work on a mathematical modelling task and detail their solution. Students should also reflect on the modelling process in order to make explicit the mathematics that they used and how well they understood it. This cycle also highlights the iterative nature of mathematical modelling. Revisions of a solution should take place and students may progress in different ways through the modelling cycle before developing an adequate solution. For this to occur modelling activities should be open-ended.

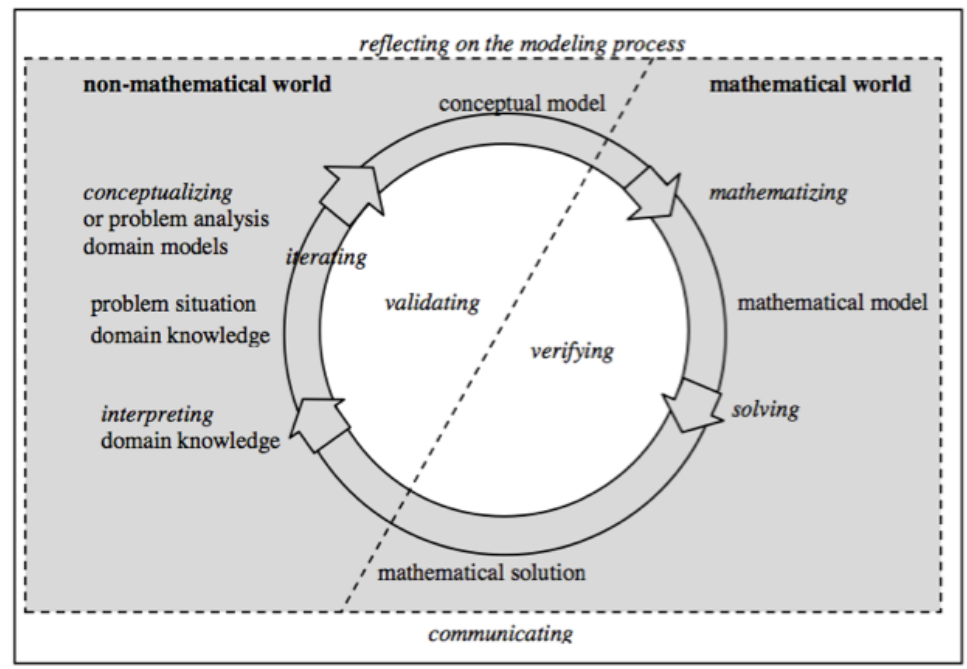

Figure 2. Perrenet \& Zwaneveld's (2012) modeling cycle

A modelling cycle that appears often in the literature is from Blum and LeiB (2007) and connects to several essential elements. Again there is a distinction between the real world and mathematics. It can be seen that students must make sense of the problem with mathematics and ensure that the model developed makes sense in the realistic context. Though not shown we know that the modelling process is iterative in nature (e.g. Arleback 2009b). 


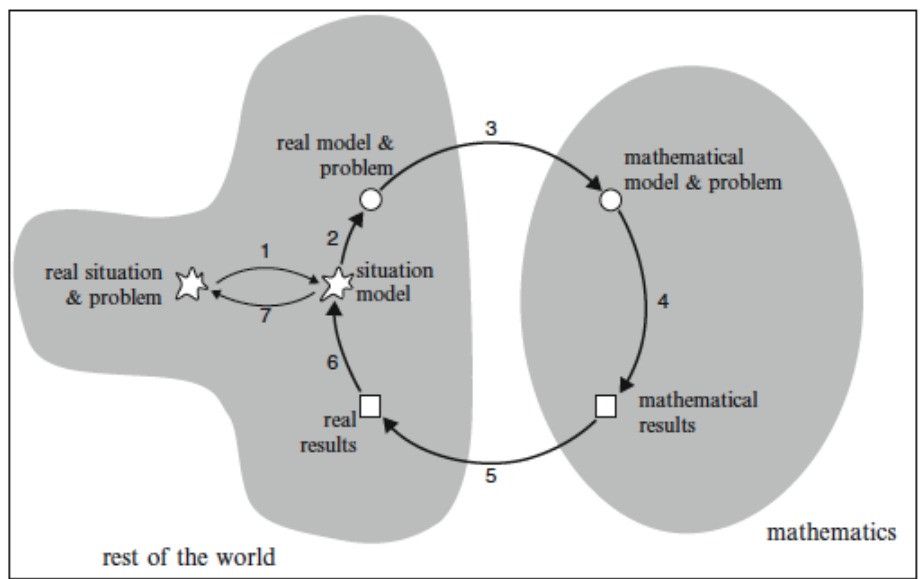

Figure 3. Blum and LeiB (2007) modeling cycle

In summary, there are seven essential elements of mathematical modelling: (a) start with a real world problem, (b) work from key questions (c) make sense of the problem with mathematics often involving assumptions and approximations, (d) ensure the mathematics is accurate and makes sense in the realistic situation, (e) goal of clear verbal and written communication throughout often including multiple representations, (f) modelling is an iterative process that involves open-ended problems, and $(\mathrm{g})$ reflection on mathematics used or the modelling process (Stohlmann \& Albarracin, 2016).

There are different theoretical perspectives for mathematical modelling-realistic, contextual, educational, socio-critical, epistemological, and cognitive (Kaiser \& Sriraman, 2006) and the essential elements are common ground for the different persepectives. The main mathematical modelling theoretical perspective for contextual modelling, The Models and Modelling Perspective, is discussed more in the following section because the most frequent modelling curricula that was used in the articles were Model-Eliciting Activities that are based on the Models and Modelling Perspective.

\subsection{Models and Modelling Perspective (MMP)}

The MMP has been shown to be a powerful conceptual framework for research on the interacting development of students and curricula resources. This perspective focuses on the noun construct as well was the verb construct. Students' development of powerful constructs or conceptual systems is among the most important goals of mathematics instruction. The MMP also emphasizes the noun model as significant as the verb model (Lesh \& Doerr, 2003b). In general, "models are conceptual systems (consisting of elements, relations, operations and rules governing interactions) that are expressed using external notation systems, and that are used to construct, describe, or explain the behaviors of other system(s) - perhaps so that the other system can be manipulated or predicted intelligently" (Lesh \& Doerr, 2003a). MMP is based on the idea that students do not only engage their mathematical understandings in solving problems but also their beliefs, values, and feelings. This can be drawn from experiences that tend to be developed from specific contexts (Lesh, Carmona, \& Moore, 2009). In order to make this knowledge more transferable it is important for students to generalize knowledge, solution strategies, and models to other closely-related problems or situations. This is built into a mathematical modelling curricula activity based on the MMP called Model-Eliciting Activities (MEAs). MEAs are client driven, open-ended, realistic problems that are developed based on six principles. Often while completing an MEA students will refine, revise, and extend powerful mathematics constructs (Lesh \& Doerr, 2003a).

\section{Methods}

The results of this paper stem from a literature search for empirical studies involving middle and high school mathematical modelling. Articles that were theoretical or that described mathematical modelling activities without description of a research study connected with the activities were not included. Adequate papers were identified through a targeted and a general literature search. The targeted literature search involved looking at the edited books arising from the International Community of Teachers of Mathematical Modelling and Applications (ICTMA) conferences; as well as the conference proceedings of the thematic working groups in the Congresses of the European Society for Research in Mathematics Education (CERME). Also looked at was the International Commission on Mathematical Instruction (ICMI) 14 study on modelling and applications in mathematics education. Specific journals were looked at which included the Journal of Mathematical Modelling and Application, Educational Studies in Mathematics, and Teaching Mathematics and its Applications. Special issues of journals that focused on mathematical modelling were 
also investigated which included two issues of ZDM from 2006, one issue of Mathematical Thinking and Learning from 2003, and one issue of the Journal of Mathematics Education at Teachers College in 2013. The general literature search went back to 1970 and involved searches for mathematical modelling high school, mathematical modelling middle school, mathematical modelling junior high, mathematical modelling mathematics education, mathematical modelling, and Model-Eliciting Activities.

Using a method similar to Diaz and Cox (2012), who summarized engineering education articles, all empirical studies that involved mathematical modelling in middle and high school that also meet the essential elements of mathematical modelling were summarized using the categories of assessment data collected, unit of analysis studied, population, and effectiveness. There were sixty-seven publications identified. Table 1 describes the number of articles identified from each journal, book, or conference. Once this was completed, each category was quantitatively summarized by looking at similarities in assessment data, unit of analysis or population. Areas of future research were identified throughout the process of organizing and categorizing the literature review.

Table 1. Summary of location of identified publications from literature search

\begin{tabular}{lc}
\multicolumn{1}{c}{ Journal, book, or conference } & $\begin{array}{c}\text { Number of } \\
\text { publications }\end{array}$ \\
\hline $\begin{array}{l}\text { International Community of Teachers of Mathematical Modelling and Applications } \\
\text { (ICTMA) edited book chapters }\end{array}$ & 34 \\
$\begin{array}{l}\text { Congresses of the European Society for Research in Mathematics Education (CERME) } \\
\text { proceedings }\end{array}$ & 7 \\
Book: Beyond Constructivism: Foundations of a models and modeling perspective on \\
mathematics teaching, learning, and problem solving & 5 \\
ZDM & \\
Educational Studies in Mathematics & 4 \\
International Commission on Mathematical Instruction (ICMI) 14 study on modeling & 4 \\
and applications in mathematics education & 3 \\
Mathematical Thinking and Learning & \\
Journal for Research in Mathematics Education & 3 \\
Teaching Mathematics and its Applications & 1 \\
Journal of Mathematical Modelling and Application & 1 \\
Journal of Mathematics Education at Teachers College & 1 \\
The Montana Mathematics Enthusiast & 1 \\
Journal fur Mathematik-Didaktik & 1 \\
Mind, Culture, and Activity & 1 \\
\hline
\end{tabular}

\section{Results}

\subsection{Assessment Data Collected}

This section will summarize the data sources collected in the studies and the data analysis methods. An interesting data source used in four studies was having audio recordings of students' reflections as they watched video of themselves solving a problem (e.g. Busse \& Kaiser, 2003). It was used to get students to reflect on how they worked with the real world situation in the problem. Using this method, four types of dealing with the real world context were identified by Busse (2011): reality bound, mathematics bound, integrating, and ambivalent.

The data analysis methods were mainly qualitative but there were fifteen instances of quantitative data analysis. These included eight studies with descriptive statistics of test results, four uses of ANOVA, two t-tests, one Mann Whitney U Test, and one latent growth modelling. There were twelve studies that did not state or describe their data analysis methods. The qualitative analysis methods included grounded theory, describing pre-determined categories of interest, discourse analysis, the use of rubrics, and coding done based on various frameworks. The frameworks used included Arleback's (2009b) Modelling Activity Diagram (MAD). The MAD framework is used to display the time spent on each part of six modelling sub-activities and how the participants iterate through the modelling process. The six sub-activities used are reading, making model, estimating, validating, calculating, and writing. Another framework used 
was Sfard's (2008) framework of commognition. This framework combines insights from theories of communication and cognition. This framework can be used to analyze inter and intrapersonal communication while attending to both the social and cognitive dimensions of modelling (Arleback \& Frejd, 2013). With multiple MEAs Lesh and Harel (2003) used Piaget's stages of development for proportional reasoning to show how students can progress through the stages during one modelling session.

A couple of studies used multiple frameworks. Harel and Lesh (2003) used the Piagetian notion of abstraction (Piaget, Inhelder, \& Szeminksa, 1960), Harel and Sowder's (1998) conceptual framework of proof scheme, and Lesh and Kaput's (1988) outline of local conceptual development. Brown and Edwards (2011) also used multiple frameworks: Busse's (2005) four types for how students deal with reality and mathematics, Stillman's (2000) classifications of prior knowledge as academic, encyclopaedic, or episodic, and Brown's (2007) higher order thinking framework.

Rubrics were also used to assess students' mathematical modelling competencies and effectiveness of the steps of the modelling process. Biccard and Wessels (2011) used a scale from 0 to 3 to assess modelling competencies from students' work on complete modelling problems. Ikeda and Stephens (2010) used a rubric with individual questions targeted at specific steps of the modelling process. Another rubric involved twenty performance goals for the assessment of modelling and used a scale of 0 to 5 for each performance goal (Lege, 2007). One of the goals did not seem to fit with mathematical modelling, stay with the plan previously made; as modelling often involves iterations that can involve students trying a new approach or idea. Students also may proceed done on an unproductive path and in these cases a new plan should be tried. Dunne and Galbraith (2003) also used a rubric to assess students' steps of the modelling process but used multiple complete modelling problems to do this. MaaB and Mischo (2011) combined both multiple choice questions targeted at specific steps of the modelling process along with an open-ended complete modelling problem to assess students' effectiveness of the modelling process. The complete modelling problem was scored based on a rubric for each step of being not comprehensible, partly comprehensible, and comprehensible.

A couple of tests were used to measure modelling competencies. MaaB (2006) used a ten task modelling pre test and a slightly modified post-test version that was designed to assess all the sub-competencies of modelling. Another test that assessed sub-competencies involved eight multiple choice items. Each question asked for the next appropriate step at a specific phase in a modelling problem (Grunewald, 2013). This test was based on existing modelling tests designed and reworked by Haines and Crouch (2001) and Houston and Neill (2003).

\subsection{Unit of Analysis}

The units of analysis of the studies fell into five categories: modelling process/sub-activities, modelling competencies/ability, blockages/difficulties during the modelling process, students' beliefs, and construction of knowledge. These categories will be discussed in further detail in the effectiveness section.

\subsection{Population}

The population of the studies varied, as well as the ages of the students and the number of students. The studies represented a good mix of ages and sample sizes though. The studies were done in a number of countries. The number of studies per country is as follows: Germany (19), USA (12), Australia (11), Sweden (5), Japan (4), Cyprus (4), Singapore (4), Portugal (2), Denmark (2), South Korea (1), South Africa (1), Brazil (1), Albania (1), Canada (1), and Spain (1).

Student demographics or school setting information was also provided in the studies. Twenty-two studies gave the number of male and female students. In twelve of the studies students had little experience with applications and modelling and in six of the studies students had prior experience with mathematical modelling. Thirteen of the studies involved high mathematics ability students, three studies involved mixed ability students, three studies average ability students, and four studies with low ability students. Nine studies were done in urban locations, two with low Social Economic Status (SES) students, two with medium SES students, two in a suburban location, and two in a rural location. Fewer studies used these characteristics in their analysis. There were three studies that looked at gender in their analysis (Bracke \& Geiger, 2011; Brown, 2013; Grunewald, 2013). There was one study that compared the solutions of high and low mathematics achieving students (Biccard \& Wessels, 2011) and one study that compared a treatment group of medium mathematics ability students with a control group of high mathematics ability students (Dunne \& Galbraith, 2003). Four studies also compared students based on different grade levels (Mousoulides et al., 2007; Mousoulides et al., 2008; Mousoulides et al., 2010; Yanagimoto \& Yoshimura, 2013).

\subsection{Effectiveness}

After reviewing all of the studies, there were five main categories into which the studies could be categorized. Each of the categories will be detailed as to what is known about the topic from the research. 


\subsubsection{Modelling Process/sub-activities}

Overall, across twenty-one studies with different grade levels and in different countries it was found that students are able to work through iterations of the modelling process in order to solve mathematical modelling problems (e.g. Arleback \& Bergsten, 2010; Lesh \& Doerr, 2003a; Mousoulides, Christou, \& Sriraman, 2008). There were two main modelling processes that were used or adapted in the studies: Blum and Leib's (2007) modelling process with description by Borromeo Ferri (2006) and Lesh and Doerr's (2003a) four step modelling process of description, manipulation, prediction, and verification. Some studies looked at just parts of the modelling process including mathematizing (e.g. Grigoras, Garcia, \& Halverscheid, 2011) and communication (e.g. Lingefjard \& Meier, 2011).

The studies also demonstrated that as students gain more experience with mathematical modelling their effectiveness of using the modelling process can improve. MaaB and Mischo (2011) conducted a study of 865 students in Germany with average age of 11.55 years with $45 \%$ of the students low SES. The researchers used both an open-ended modelling task and multiple choice questions and found that students scored an average of 1.99 on the modelling steps of the open question and 3.31 on the multiple choice questions with a range of 0 to 5 points. However, before this assessment students had little experience with applications and modelling. In a study with one class of $7^{\text {th }}$ and one class of $9^{\text {th }}$ graders in the U.S. Gould and Wasserman (2014) found that high achieving mathematics students struggled with identifying the most important variables and making assumptions with a problem on deciding the best gas station to buy gas from. In this study students were inexperienced with mathematical modelling. Also, groups could have shared their solution strategies with the rest of the class and been given more support in understanding the real world context. These studies show that mathematical modelling is something that is difficult to be proficient at with little experience and the structure of how activities are implemented is important. Studies have shown that with more experience students can improve in mathematical modelling. Ikeda and Stephens (2010) had thirty-four $9^{\text {th }}$ graders who selected mathematics as an elective subject complete four modelling tasks over three months time. The researchers found that using a pre and post questionnaire to assess modelling processes that there was a statistically significant difference for setting assumptions, validating and modifying the assumptions, what process is required to solve modelling problems, and what makes a model good.

\subsubsection{Modelling Competencies/ability}

There were twenty-six studies done in this category that looked at students' range of ideas/strategies, modelling competencies, and modelling ability. The research has shown that students produce a range of strategies or models when working on mathematical modelling (Abrantes, 1993; Albarracin \& Gorgorio, 2013; Aliprantis \& Carmona, 2003; Doerr \& English, 2003; Greefrath, 2010; Hamacher \& Kreubler, 2013; Lesh \& Doerr, 2003a; Ludwig \& Reit, 2013; Mousoulides \& English, 2011; Mousoulides et al., 2008; Stillman et al., 2013; Yanagimoto \& Yoshimura, 2013). Greefrath (2010) in working with German students age 10-16 identified three general modelling strategies: (a) reality oriented with low level mathematics, (b) focus on the realistic situation with mathematics used but not discussed, and (c) approximations and assumptions of realistic situation and correct mathematics discussed. Other studies have found different models that students have developed for a specific problem. In a study of 234 German students age 12-17, four different models were generated for a problem that asked students to determine the minimal string length of a tennis racket: direct measurement, rectangle model, functional model, and area model (Ludwig \& Reit, 2013). A study was done with 22 students age 16 in Spain that had students work with Fermi problems which require estimation of large quantities. The researchers found six categories of strategies that were used including population density and a grid approach (Albarracin \& Gorgorio, 2013). Students at different grade levels can develop different models based on their prior knowledge. Yanagimoto and Yoshimura (2013) in a study of 460 Japanese students with a problem involving population of Bluefin tuna found that $7^{\text {th }}$ graders tended to use a proportional model, $8^{\text {th }}$ graders a linear model, and $9^{\text {th }}$ graders a recursive formula. This shows how students' prior knowledge which is affected by their teachers' instruction can influence students' models used.

Modelling competencies involve the steps of the modelling process but go beyond this to "include skills and abilities to perform modelling processes appropriately and goal-oriented as well as the willingness to put these into action" (MaaB, 2006, p.117). Modelling competencies specifically entail understanding the realistic problem and setting up a model based on reality, setting up a mathematical model from the real world, solving mathematical questions within a mathematical model, interpreting mathematical results in a real solution, validating a solution, metacognition, effective communication and argumentation, and positive attitudes toward real world application problems (MaaB, 2006). Three other studies used these descriptions for their understanding of modelling competencies (Biccard \& Wessels, 2011; Grunewald, 2013; MaaB, 2007). Taking a more narrow view of modelling competencies, Ludwig and Reit (2013) have developed 6 modelling competency stages that describe how far participants progress through the modelling cycle, based on Blum and LeiB's (2007) modelling cycle. 
There are several insights from the research on modelling competencies including that the competencies develop over time and that some competencies are more difficult for students to develop. A study of 12 students, including low mathematics achieving and high mathematics achieving students, in South Africa had students complete 3 MEAs over a span of 4 months. Twelve modelling competencies were evaluated based on a four scale rubric. The students had no previous modelling experience and initially were weak in all competencies. At the end of the study the modelling competencies were more developed but interpreting and validating remained weak throughout. It was also found that mathematising was dependent on understanding and simplifying (Biccard \& Wessels, 2011). Similarly Grunewald (2013) found that 135 grade 9 students in Germany had no improvement in interpreting the solution in the realistic context using a pre and post test that assessed modelling sub-competencies. However, this study only used one modelling problem as an intervention. Overall, students significantly improved on the measure of modelling competencies. Also, similar to MaaB (2006) a positive relationship was found between mathematics ability and modelling competencies. Providing more detail into modelling competencies MaaB (2007) found that better modellers had better metacognition about the modelling process. Studies with 135 students (Grunewald, 2013) and 234 students (Ludwig \& Reit, 2013) in Germany have shown that there are no gender differences in modelling competencies of students.

The studies involving modelling abilities are connected to modelling competencies but looked specifically at groups' final models. Studies done with MEAs have found that most groups are able to develop acceptable final models (Doerr \& English, 2003; Mousoulides et al., 2008; Mousoulides \& English, 2011). A study of 640 U.S. and 14 Australian students age 11-13 found that students created generalizable and reusable models when working on five MEAs involving selecting, ranking, and weighting data (Doerr \& English, 2003). In Cyprus $6^{\text {th }}$ and $8^{\text {th }}$ grade students completed 6 MEAs over 3 months and their models improved over time. The researchers also developed a 9 task modelling abilities test that presented students with a situation with constraints that required choosing among alternative decisions. This study was an experimental design. Based on the analysis of the modelling abilities tests using latent growth modelling, the MEA intervention was most effective for students with initially low modelling abilities while low modelling abilities students in the control group had low rates of change (Mousoulides et al., 2008). Bracke and Geiger (2011) had twenty-six 14-15 year old students in Germany complete 5 modelling tasks and used sixty-nine students as a comparison group. After the modelling group had done the five tasks, both groups completed two modelling tasks based on deciding which checkout line to pick at a grocery store and how to estimate the mass of a stone formation. University personnel not associated with the project evaluated the final reports for the two tasks. The modelling group finished faster, felt the problems were easier, and did better at using appropriate formal notation. They also did better at finding solutions and quality of documentation as four teams in the control group did not come up with solutions. However, comparing the deepness of the solutions on average, the comparison group did better. No explanation is provided concerning this finding nor how deepness of solution was determined. Time spent on writing and drafting a report can contribute to its effectiveness though. A study with 9 upper secondary students in Denmark found that students' reports had little discussion of students' models or their approximations. The researchers suggested that students may not have had enough time to complete this as the modelling activity required most of the time (Andresen \& Petersen, 2011).

\subsubsection{Blockages/difficulties During the Modelling Process}

Eight studies looked at difficulties that students can have during the modelling process and found that students might have difficulties at all parts of the modelling process. Galbraith, Stillman, Brown, and Edwards (2007) developed a framework that has 31 general possible blockages between the six modelling steps and was used by Stillman, Brown, and Galbraith (2010) in their analysis of the shot on goal problem. Using the same problem Stillman (2011) identified five metacognitive responses that students could have when faced with difficulties. Several studies found that if students lacked needed mathematics knowledge it could cause a blockage (Galbraith \& Stillman, 2006; Galbraith et al., 2007; $\mathrm{Ng}$, 2011; Stillman, Brown, \& Galbraith, 2010). Another frequent blockage was caused by understanding the real world situation (Blum \& LeiB, 2007; Busse \& Kaiser, 2003; Galbraith et al., 2007; Ng, 2011; Stillman et al., 2010). If students do not understand the context and what is being asked then it can be difficult to develop an appropriate model. In addition, the more the consistency with the real world is emphasized the more difficult it can be to solve a problem (Ikeda, 1997). While time may need to be spent ensuring that students have needed background knowledge on the real world context, the real world context also provides motivation for students (Busee \& Kaiser, 2003). Use of technology was found to help students continue through the modelling process (Galbraith et al., 2007) but also a cause of blockage if students are unfamiliar with how to use the technology (Galbraith \& Stillman, 2006).

Duration of the modelling problem can also lead to difficulties. Ng (2011) conducted a case study of one class of 13-14 year old students in Singapore in which the task was to design an environmentally friendly building and create a scale model. The activity lasted 15 class sessions and the researcher found that the students lost motivation and interest in the 
project. For longer modelling activities, others have suggested allowing students to chose a situation of their own to model. Abrantes (1993) investigated four classes of students age 12 to 15 in Portugal who worked for 4 weeks on group selected projects. She found that the projects were the most frequent topics of conversation between students and their parents about what happens in mathematics class. In the eight studies, MEAs were not used. The structure of MEAs, including the self-assessment principle, and their implementation method, having groups share and discuss their ideas and then time for revision, could help to alleviate difficulties that students can have during the modelling process.

\subsubsection{Students' Beliefs}

Twelve studies looked at students' beliefs in regards to mathematical modelling and applications, mathematics, and mathematics teaching. The research has found that students have mostly positive views towards mathematical modelling after multiple mathematical modelling experiences (Bracke \& Geiger, 2011; Dunne \& Galbraith, 2003; Kaiser \& Maab, 2007; Kaiser \& Stender, 2013; MaaB, 2010). Two classes of German students, age 13-14, participated in six modelling units over 15 months time. Students with an application oriented or dynamic belief system had positive attitudes towards modelling while students with a static or more formalism-oriented belief system rejected mathematical modelling (Kaiser \& Maab, 2007). Bracke \& Geiger (2011) used five modelling tasks with one class of 14-15 year old German students and found that boys and girls enjoyed modelling, but girls' interest decreased slightly over the five modelling tasks. The context of the modelling problems could have affected this. In a study of several hundred age 14-15 year old German students paired with university students as mentors it was found that students had mainly positive views on mathematical modelling. The students found the tasks to be well-structured, realistic, difficult, and interesting (Kaiser \& Stender, 2013).

Studies that have looked at students' beliefs about mathematics after mathematical modelling experiences have shown mainly that students come to see mathematics as more real life and applicable (Galbraith \& Clatworthy, 1990; Kaiser \& Schwarz, 2006; Kaiser, Schwarz, \& Buchholtz, 2011; MaaB, 2010; Yanagimoto \& Yoshimura, 2013). Four hundred and sixty $7^{\text {th }}-$ th $^{\text {th }}$ grade Japanese students participated in a problem to model the population of Bluefin tuna. After the activity the students realized that mathematics is helpful for the real world (Yanagimoto \& Yoshimura, 2013). In Germany, two-hundred eighty nine students age 16-18 completed a 1 week modelling problem and became more aware of the relevance of mathematics in their life (Kaiser, Schwarz, \& Buchholtz, 2011). In contrast a year long study with a modelling treatment class and a traditional control class of 12 year old students in Germany found little change in beliefs about mathematics for either class. The beliefs about mathematics that were measured by a Likert survey (Aiken, 1979) were related to enjoyment, motivation, importance, and freedom from fear. The total scores could range from 24 (positive) to 72 (negative). The pre-post means for the treatment class were 36.7 and 35.8; while it was 30.8 and 31.1 for the control class. Little information is given about the modelling intervention or the teacher's experience with modelling (Dunne \& Galbraith, 2003). Another study that was done in Germany with 224 ninth grade students used a pre and post Likert survey to assess the students' beliefs on enjoyment, value, interest, and self-efficacy for modelling problems, word problems, and mathematics with no real world context. It was found there was no difference in students' beliefs for the three problem types. However, the study lasted only two weeks and all three problem types were done during the two weeks, not solely modelling (Schukajlow, Leiss, Pekrun, Blum, Muller, \& Messner, 2011).

Two studies that were done outside of the regular school setting investigated if students would like to have mathematical modelling included in their regular mathematics classes. Kaiser et al. (2011) found that students wanted to have mathematical modelling included in their regular school teaching. Another study with the same lead author found that students felt that the skills they learned during the mathematical modelling experience could be used in many fields. However, while the majority of students wanted modelling in their regular mathematics classes, some students did not because they felt it was too time consuming (Kaiser \& Stender, 2013).

\subsubsection{Construction of Knowledge}

Eleven studies looked at students' knowledge construction during mathematical modelling and mainly found that students are able to construct developing mathematical understandings (Arleback, Doerr, \& O'Neil, 2013; Brown \& Edwards, 2011; Carmona, 2003; Dunne \& Galbraith, 2003; Hitt \& Gonzalez-Martin, 2015; Lesh \& Carmona, 2003; Lesh \& Doerr, 2003a; Lesh \& Harel, 2003; Harel \& Lesh, 2003; Ng, 2011; Park, Park, Park, Cho \& Lee, 2013). Six of the studies involved MEAs done in the U.S. in which students were able to reason with concepts of average rate of change with exponential functions (Arleback, Doerr, \& O'Neil, 2013), inverse variation (Carmona, 2003), proportionality (Lesh \& Doerr, 2003a; Lesh \& Harel, 2003), geometry and measurement (Lesh \& Carmona, 2003), and transformational proof scheme that involves pictorial anticipation of an action not yet performed (Harel \& Lesh, 2003). Five of the studies were done with average or low ability middle school students age 11-13. A limitation of these studies however is that four of the studies involved only 3 students and one did not specify the number of students. Other studies have had larger sample sizes but were done with medium or high mathematics ability students. A study with 
fifty-one students that were going to enroll as first year university engineering majors found over the course of six weeks that students could work with exponential functions as well as reason with directionality in terms of speed, velocity, and average rate of change but had greater difficulty with negative rate of change (Arleback et al., 2013). Park et al. (2013) showed that a mathematical modelling activity supported conceptualization in calculus through various representations and iterations of thinking with one class of high ability $8^{\text {th }}$ grade students in South Korea. Another study (Dunne \& Galbraith, 2003) with 12 year-old students in Australia compared the basic mathematics content and skill knowledge of a medium mathematics ability modelling treatment group with a high mathematics ability control group over the course of a year. The modelling treatment class used modelling problems to introduce concepts and then had traditional instruction after that. The modelling class had statistically significant higher mathematics achievement after the year compared to the high ability control group. However, a year later both classes of students had a traditional class and then the high ability students outscored the modelling treatment class.

\section{Discussion}

Mathematical modelling is an invaluable part of mathematics to help students develop competencies and knowledge that they will need to be successful in the technological based, global, and changing world that we live in. This paper summarized the research on secondary grades mathematical modelling (ages 11-18) and found that there were five main units of analysis that have been studied.

\subsection{Modelling Competencies/abilities}

Modelling competencies encompass a variety of concepts, which can make measuring the total construct of modelling competencies difficult. MaaB and Mischo (2011) described in detail the development of their instrument for measuring modelling competencies while others are based on existing tests (Grunewald, 2013), or existing modelling tasks (MaaB, 2006). More research is needed though on refinement or development of instruments that can best fully measure modelling competencies. MaaB's (2006) definition of modelling competencies can be used as further studies explore the extent to which modelling competencies are transferable across content areas and contexts. Also, rather than just describing the modelling competencies and abilities at a single point in time, we need studies of how these competencies or abilities can develop over time with longitudinal studies (English, Lesh, \& Fennewald, 2008). Looking at transferability, the generalizability principle for developing MEAs is useful as students are required to develop a model for not only the immediate situation but also for closely related situations (Lesh, Hoover, Hole, Kelly, \& Post, 2000).

\subsection{Modelling Process}

For modelling processes, frameworks or rubrics can be further refined or developed. Arleback (2009) has recommended further research using the Modelling Activity Diagram (MAD) framework to also look at individual contributions to group modelling. Another option is to use Borromeo Ferri's (2006) construct of individual modelling route, which encompasses students' passage through the different phases of the modelling cycle, which is revealed through their use of different representations. Two main modelling processes that have been employed frequently in studies can be continued to be used: Blum \& LeiB's (2007) modelling process with description by Borromeo Ferri (2006) and Lesh and Doerr's (2003a) four step modelling process. Further research can investigate students' individual ability and interactive ability in solving mathematical modelling problems and how to accurately assess both.

\subsection{Construction of Knowledge}

The research on construction of knowledge with mathematical modelling can be expanded. Both Park et al. (2013) and Arleback et al. (2013) suggested research focused on mathematical modelling with additional mathematical concepts. This can be done by having studies use a modelling treatment group and a control group to further document the effectiveness of mathematical modelling. The modelling treatment group can employ a method similar to the "island" approach (Blum \& Niss, 1991) in which mathematical modelling is integrated as a formative assessment or a supplement to normal teaching. Promising results have been shown with this approach (Dunne \& Galbraith, 2003) but more research can be done with different aged students and with larger samples. Key questions to guide this work include: What would be an appropriate balance-in terms of attention, time and effort---between applications and modelling activities and other mathematical activities in mathematics classrooms at the secondary level? (Blum et al., 2002) "When applications and modelling are included at different places in mathematics curricula, how can it be guaranteed that basic modelling skills and competencies are acquired systematically and coherently?" (Blum et al., 2002).

In order for this to occur it is imperative to identify "big ideas" that modelling curricula can be built around. Lesh (2010) stated three main questions that deserve focus for how students construct mathematical knowledge through modelling: (a) "What are the most important 'big ideas' that should be emphasized in a given mathematics topic area?, (b) What 
does it mean to 'understand' these ideas? and (c) How do these understandings develop?" (p.16). In the U.S. Common Core State Standards for Mathematics [CCSSM], 2010) sixteen high school content standards are highlighted as modelling standards. This can be beneficial for teachers and researchers to have a specific focus on concepts that best lend themselves to be developed through modelling.

\subsection{Students'Beliefs}

Students' beliefs are an important construct as beliefs are the best indicators of the decisions that individuals make throughout their lives (Pajares, 1992). Realistic contexts of modelling activities can lead to student engagement but more research is needed on the realistic contexts that positively engage a diverse range of students (Mousoulides et al., 2008). A few questions that can be researched connected to beliefs include: What is the potential of mathematical modelling to support both students and teachers in their development of appropriate beliefs about and attitudes towards mathematics? How do attitudes and beliefs affect the models that students create? This is important because when students design models, they tend to do more than simply engage logical-mathematical systems. They also engage feelings, values, and beliefs making these integral parts of models (English, Lesh, \& Fennewald, 2008).

\subsection{Future Research}

There are several other areas of research that can be undertaken to broaden the research base for mathematical modelling. Several studies stated the importance of teachers' knowledge and experience with mathematical modelling (Gould \& Wasserman, 2014; MaaB, 2006; MaaB, 2007). Future research can focus on linking teachers' content knowledge and experiences specific to mathematical modelling (Doerr, 2007) with student outcomes. In general, there is research that shows that teachers' mathematical content knowledge is positively related to students' mathematics achievement (Campbell et al., 2014). More research could be done though specific to mathematical modelling and the impact of teachers on the effectiveness of mathematical modelling. This is important because teachers with limited experience with mathematical modelling can implement it poorly leading to negative student outcomes (Cheng, 2013).

Research from mathematical modelling at the elementary level with multi-tiered teaching experiements (Lesh \& Kelly, 2000) can be used to guide this work. A quality example of this is English's (2009) three-year longitudinal study of four classes of 3rd grade students. At the first level of a multi-tiered teaching experiment students create models in their work. At the second and third level the teachers work with the researcher in designing and implementing the modelling problems. The modelling activities challenge the teachers as they consider the mathematical ideas that students might use and the best ways to respond to students' ideas. Researchers make sense of both the students' models and the teachers' implementation of the modelling activities. A related approach that has been used at the secondary level is in the investigation of meta-metacognition (Stillman, 2011). Here teachers think about and explore students' metacognition while the researcher can make sense of both the students' metacognition and the teachers' meta-metacognition. In general, some form of professional development or training for teachers in studies should be provided to assist teachers in proper implementation of mathematical modelling (e.g. English \& Watters, 2005; English, 2009).

Integrating STEM education with mathematical modelling is a natural fit that deserves more attention. While there were several studies that discussed the impact of technology with mathematical modelling (Brown \& Edwards, 2011; Galbraith \& Stillman, 2006; Galbraith et al., 2007), students' interactions with technology were the not the main focus of the studies. More research can be done on effective technological tools that benefit students during mathematical modelling and are worth the time investment for students to learn their usage. A question to guide this work is "In what cases is technology a crucial need in modelling in the classroom? Are there circumstances (if any) where modelling processes can't be developed without technology? (Blum et al., 2002). Two main considerations for technology integration are will the technology allow students to do something that they could not have done before and also will the technology allow students to do something they could have done before but in a better way.

Many of the modelling activities had real world science contexts, for example non-renewable energy sources and animal populations, that make for natural connections for students to learn science content or concepts along with the mathematics content. Mathematical modelling is often also a natural way for students to learn more about engineering. Mathematical modelling and predictive analysis are essential to engineering, and engineers must be comfortable applying mathematics (National Academy of Engineering, 2009). Future research can focus on how engineering can be best integrated with mathematical modelling (Goold, 2015; Mousoulides \& English, 2011).

\subsection{Conclusion}

In conclusion, Aliprantis and Carmona (2003) state, "all students are capable of learning and developing powerful mathematical concepts" (p.264). Mathematical modelling is an effective way to ensure that this happens and there are many committed and thoughtful individuals putting efforts into the research base for effective mathematical modelling at the secondary level. Mathematical modelling has many benefits and all students should be encouraged and supported to develop with this approach. 


\section{References}

Abrantes, P. (1993). Project work in school mathematics. In J. deLange, I. Huntley, C. Keitel, \& M. Niss. (Eds.), Innovation in maths education by modelling and applications (pp.355-364). New York: Ellis Horwood.

Aiken, L. (1979). Attitudes towards mathematics and science in Iranian schools. School Science and Mathematics, 79, 229-234. http://dx.doi.org/10.1111/j.1949-8594.1979.tb09490.x

Albarracin, L., \& Gorgorio, N. (2013). Fermi problems involving big numbers: adapting a model to different situations. In B. Ubuz, C. Haser, \& M.A. Mariotti. (Eds.) Proceedings of the Eighth Congress of the European Society for Research in Mathematics Education (pp.930-939). Ankara, Turkey: European Society for Research in Mathematics Education.

Aliprantis, C., \& Carmona, G. (2003). Introduction to an economic problem: A models and modeling perspective. In R. Lesh \& H. Doerr (Eds.), Beyond constructivism: models and modeling perspectives on mathematics problem solving, teaching, and learning (pp.255-264). New York: Routledge.

Andresen, M., \& Petersen, A. (2011). Modelling chemical equilibrium in school mathematics with technology. In G. Kaiser, W. Blum, R. Borromeo Ferri, \& G. Stillman (Eds.), Trends in teaching and learning of mathematical modelling (pp.519-528). New York: Springer. http://dx.doi.org/10.1007/978-94-007-0910-2_51

Arleback, J., Doerr, H., \& O’Neil, A. (2013). A modelling perspective on interpreting rates of change in context. Mathematical Thinking and Learning, 15, 314-336. http://dx.doi.org/10.1080/10986065.2013.834405

Arleback, J., \& Frejd, P. (2013). Modelling from the perspective of commognition-An emerging framework. In G. Stillman, G. Kaiser, W. Blum, \& J. Brown (Eds.). Teaching mathematical modelling: Connecting to research and practice (pp.47-56). New York: Springer. http://dx.doi.org/10.1007/978-94-007-6540-5_3

Arleback, J. B. (2011). Exploring the solving process of groups solving realistic Fermi problem from the perspective of the anthropological theory of didactics. In M. Pytlak, T. Rowland, \& E. Swoboda, (Eds.), Proceedings of the Seventh Congress of the European Society for Research in Mathematics Education (pp. 1010-1019). Rzeszow, Poland: European Society for Research in Mathematics Education.

Arleback, J., \& Bergsten, C. (2010). On the use of realistic Fermi problems in introducing mathematical modelling in upper secondary mathematics. In R. Lesh, P. Galbraith, C. Haines, \& A. Hurford (Eds.), Modeling students' mathematical modeling competencies (pp.597-609). New York: Springer. http://dx.doi.org/10.1007/978-1-4419-0561-1_52

Ärlebäck, J. B. (2009a). Mathematical modelling in upper secondary mathematics education in Sweden. A curricula and design study. (Doctoral Dissertation). Retrieved from diva-portal.org (diva2:302720).

Arleback, J.B. (2009b). On the use of realistic Fermi problems for introducing mathematical modelling in school. The Montana Mathematics Enthusiast, 6(3), 331-364.

Australian Curriculum, Assessment and Reporting Authority (2015). http://www.australiancurriculum.edu.au/mathematics/curriculum/f-10?layout=1

Barbosa, J. C. (2006). Mathematical modelling in classroom: a socio-critical and discursive perspective. ZDM, 38(3), 293-301. http://dx.doi.org/10.1007/BF02652812

Biccard, P., \& Wessels, D. (2011). Documenting the development of modelling competencies of grade 7 mathematics students. In G. Kaiser, W. Blum, R. Borromeo Ferri, \& G. Stillman (Eds.), Trends in teaching and learning of mathematical modelling. (pp.375-383). New York: Springer. http://dx.doi.org/10.1007/978-94-007-0910-2_37

Blum, W., \& Borromeo Ferri, R. (2009). Mathematical modelling: Can it be taught and learnt? Journal of Mathematical Modelling and Application, 1(1), 45-58.

Blum, W., \& LeiB, D. (2007). How do students and teachers deal with modelling problems. In C. Haines, P. Galbraith, W. Blum, \& S. Khan (Eds.), Mathematical modelling: Education, engineering and economics (pp.222-231). Chichester, England: Horwood Publishing. http://dx.doi.org/10.1533/9780857099419.5.221

Blum, W., Alsina, C., Biembengut, M. S., Bouleau, N., Confrey, J., Galbraith, P., Ikeda, T., Linegefjard, T., Muller, E., Niss, M., Verschaffel, L., Wang, S., Hodgson, B., \& Henn, H.W. (2002). ICMI Study 14: Applications and modelling in mathematics education-discussion document. Educational Studies in Mathematics, 51, $149-171$. http://dx.doi.org/10.1023/A:1022435827400

Blum, W., \& Niss, M. (1991). Applied mathematical problem solving, modelling, applications, and links to other subjects-State, trends issues in mathematics instruction. Educational Studies in Mathematics, 22(1), 37-68. 
http://dx.doi.org/10.1007/BF00302716

Borromeo Ferri, R. (2006). Theoretical and empirical differentiations of phases in the modelling process. Zentralblatt für Didaktik der Mathematik, 38(2), 86-95. http://dx.doi.org/10.1007/BF02655883

Bracke, M., \& Geiger, A. (2011). Real-world modelling in regular lessons: A long-term experiment. In G. Kaiser, W. Blum, R. Borromeo Ferri, \& G. Stillman (Eds.), Trends in teaching and learning of mathematical modelling. (pp.529-549). New York: Springer. http://dx.doi.org/10.1007/978-94-007-0910-2_52

Brown, J. P. (2013). Inducting year 6 students into "A culture of mathematising as a practice.” In G. Stillman, G. Kaiser, W. Blum, \& J. Brown (Eds.), Teaching mathematical modelling: Connecting to research and practice (pp.295-305). New York: Springer. http://dx.doi.org/10.1007/978-94-007-6540-5_24

Brown, J. P., \& Edwards, I. (2011). Modelling tasks: insight into mathematical understanding. In G. Kaiser, W. Blum, R. Borromeo Ferri, \& G. Stillman (Eds.), Trends in teaching and learning of mathematical modelling. (pp.187-197). New York: Springer. http://dx.doi.org/10.1007/978-94-007-0910-2_20

Brown, J. (2007). Early notions of functions in a technology-rich teaching and learning environment (TRTLE). In J. Watson \& K. Beswick (Eds.), Proceedings of MERGA30 (1, pp. 153-162). Adelaide: MERGA.

Busse, A. (2011). Upper secondary students' handling of real-world contexts. In G. Kaiser, W. Blum, R. Borromeo Ferri, \& G. Stillman (Eds.), Trends in teaching and learning of mathematical modelling. (pp.37-46). New York: Springer. http://dx.doi.org/10.1007/978-94-007-0910-2_5

Busse, A. (2005). Individual ways of dealing with the context of realistic tasks-first steps towards a typology. Zentralblatt fur Didaktik der Mathematik, 37(5), 354-360. http://dx.doi.org/10.1007/s11858-005-0023-3

Busse, A., \& Kaiser, G. (2003). Context in application and modelling - an empirical approach. In Q. Ye, W. Blum, K. Houston, \& Q. Jiang (Eds.), Mathematical modelling in education and culture. (pp.3-15). Chichester, England: Horwood. http://dx.doi.org/10.1533/9780857099556.1.1

Campbell, P., Nishio, M., Smith, T., Clark, L., Conant, D., Rust, A., DePiper, J., Frank, T., Griffin, M., \& Choi, Y. (2014). The relationship between teachers' mathematical content and pedagogical knowledge, teachers' perceptions, and student achievement. Journal for Research in Mathematics Education, 45(4), 419-459. http://dx.doi.org/10.5951/jresematheduc.45.4.0419

Carmona, G. (2003). Three interacting dimensions in the development of mathematical knowledge. In S. Lamon, W. Parker, \& S. Houston (Eds.), Mathematical modelling: A way of life. (pp.61-69). Chichester, England: Horwood. http://dx.doi.org/10.1533/9780857099549.2.61

Carreira, S., \& Baioa, A. M. (2015, February). Assessing the best staircase: students' modelling based on experimentation with real objects. Paper presented at 9th Conference on European Research in Mathematics Education (CERME-9). Prague, Czech Republic.

Cheng, A. K. (2013). Real-life modelling within a traditional curriculum: Lessons from a Singapore experience. In G. Stillman, G. Kaiser, W. Blum, \& J. Brown (Eds.), Teaching mathematical modelling: Connecting to research and practice (pp.131-140). New York: Springer.

Common core state standards initiative (2010). Common core standards for mathematics. Retrieved from http://www.corestandards.org/assets/CCSI_Math\%20Standards.pdf

Diaz, N. V., \& Cox, M. F. (2012). An overview of the literature: Research in P-12 Engineering Education. Advances in Engineering Education, 1-37.

Djepaxhija, B., Vos, P., \& Fuglestad, A. B.(2015, February). Exploring grade 9 students' assumption making when mathematizing. Paper presented at 9th Conference on European Research in Mathematics Education (CERME-9). Prague, Czech Republic.

Doerr. H. M., \& Arleback, J. B. (2015). Fostering students' independence in modelling activities. Paper presented at 9th Conference on European Research in Mathematics Education (CERME-9). Prague, Czech Republic.

Doerr, H., \& English, L. D. (2003). A modeling perspective on students' mathematical reasoning about data. Journal for Research in Mathematics Education, 34(2), 110-136. http://dx.doi.org/10.2307/30034902

Doerr, H. (2007). What knowledge do teachers need for teaching mathematics through applications and modelling? In W. Blum, P. Galbraith, H. Henn, \& M. Niss (Eds.), Modelling and applications in mathematics education (pp.69-78). New York: Springer. http://dx.doi.org/10.1007/978-0-387-29822-1_5

Dunne, T., \& Galbraith, P. (2003). Mathematical modelling as pedagogy: Impact of an immersion programme. In Q. Ye, 
W. Blum, K. Houston, \& Q. Jiang (Eds.), Mathematical modelling in education and culture. (pp.16-30). Chichester, England: Horwood. http://dx.doi.org/10.1533/9780857099556.1.16

English, L. (2013). Complex modelling in the primary and middle school years: An interdisciplinary approach. In G. Stillman, G. Kaiser, W. Blum, \& J. Brown (Eds.), Teaching mathematical modelling: Connecting to research and practice (pp.491-505). New York: Springer. http://dx.doi.org/10.1007/978-94-007-6540-5_42

English, L. (2009). Promoting interdisciplinarity through mathematical modelling. ZDM, 41, 161 - 181. http://dx.doi.org/10.1007/s11858-008-0106-z

English, L., \& Watters, J. (2005). Mathematical modelling in the early years. Mathematics Education Research Journal, 16(2), 58-79. http://dx.doi.org/10.1007/BF03217401

Eric, C. C. (2013). Students' designing an ideal tourism route as mathematical modelling. In G. Stillman, G. Kaiser, W. Blum, \& J. Brown (Eds.), Teaching mathematical modelling: Connecting to research and practice (pp.153-163). New York: Springer.

Galbriath, P., Stillman, G., Brown, J., \& Edwards, I. (2007). Facilitating middle secondary modelling competencies. In C. Haines, P. Galbraith, W. Blum, \& S. Khan (Eds.), Mathematical modelling: Education, engineering and economics (pp.130-140). Chichester, England: Horwood Publishing. http://dx.doi.org/10.1533/9780857099419.3.130

Galbraith, P., \& Stillman, G. (2006). A framework for identifying student blockages during transitions in the modeling process. ZDM, The International Journal on Mathematics Education, 38(2), 143-162. http://dx.doi.org/10.1007/BF02655886

Galbraith, P., \& Clatworthy, N. (1990). Beyond standard models -meeting the challenge of modelling. Educational Studies in Mathematics, 21, 137-163. http://dx.doi.org/10.1007/BF00304899

Goold, E. (2015). Investigating engineering practice is valuable for mathematics learning. Teaching Mathematics and Its Applications, 34, 3-15. http://dx.doi.org/10.1093/teamat/hru026

Gould, H., \& Wasserman, N. H. (2014). Striking a balance: students' tendencies to oversimplify or overcomplicate in mathematical modeling. Journal of Mathematics Education at Teachers College, 5(1), 27-34.

Greefrath, G. (2010). Analysis of modeling problem solutions with methods of problem solving. In R. Lesh, P. Galbraith, C. Haines, \& A. Hurford (Eds.), Modeling students' mathematical modeling competencies (pp.265-271). New York: Springer. http://dx.doi.org/10.1007/978-1-4419-0561-1_23

Grigoras, R., Garcia, F., \& Halverscheid, S. (2011). Examining mathematising activities in modelling tasks with a hidden mathematical character. In G. Kaiser, W. Blum, R. Borromeo Ferri, \& G. Stillman (Eds.), Trends in teaching and learning of mathematical modelling. (pp.85-95). New York: Springer. http://dx.doi.org/10.1007/978-94-007-0910-2_10

Grunewald, S. (2013). The development of modelling competencies by year 9 students: Effects of a modelling project. In G. Stillman, G. Kaiser, W. Blum, \& J. Brown (Eds.), Teaching mathematical modelling: Connecting to research and practice (pp.185-194). New York: Springer. http://dx.doi.org/10.1007/978-94-007-6540-5_16

Frejd, P. (2013). Modes of modelling assessment-a literature review. Educational Studies in Mathematics, 84, 413-438. http://dx.doi.org/10.1007/s10649-013-9491-5

Haines, C., \& Crouch, R. (2001). Recognizing constructs within mathematical modelling. Teaching Mathematics and Its Applications, 20(3), 129-138. http://dx.doi.org/10.1093/teamat/20.3.129

Hamacher, H. W., \& KreuBler, J. (2013). Merging educational and applied mathematics: the example of locating bus stops. In B. Ubuz, C. Haser, \& M. A. Mariotti (Eds.), Proceedings of the Eighth Congress of the European Society for Research in Mathematics Education. (pp.1087-1096). Ankara, Turkey: European Society for Research in Mathematics Education.

Harel, G., \& Lesh, R. (2003). Local conceptual development of proof schemes in a cooperative learning setting. In R. Lesh \& H. Doerr (Eds.), Beyond constructivism: Models and modeling perspectives on mathematics problem solving, teaching, and learning (pp.359-382). New York: Routledge.

Harel, G., \& Sowder, J. (1998). Students' proof schemes. In E. Dubinsky, A. Schoenfeld, \& J. Kaput (Eds.), Research on collegiate mathematics education. (Vol. III, p.234-283). Providence, Rhode Island: American Mathematical Society. http://dx.doi.org/10.1090/cbmath/007/07

Hitt, F., \& Gonzalez-Martin, A. (2015). Covariation between variables in a modelling process: The ACODESA 
(collaborative learning, scientific debate and self-reflection) method. Educational Studies in Mathematics, 88, 201-219. http://dx.doi.org/10.1007/s10649-014-9578-7

Houston, K., \& Neill, N. (2003). Assessing modelling skills. In S. J. Lamon, W. A. Parker, \& S. K. Houston (Eds.), Mathematical modelling: A way of life ICTMA11 (pp.155-164). Chichester: Horwood. http://dx.doi.org/10.1533/9780857099549.4.153

Ikeda, T., \& Stephens, M. (2010). Three teaching principles for fostering students' thinking about modelling: An experimental teaching program for $9^{\text {th }}$ grade students in Japan. Journal of Mathematical Modelling and Application, $1(2), 49-59$.

Ikeda, T. (1997). A case study of instruction and assessment in mathematical modelling-'the delivering problem'. In S. K. Houston, W. Blum, I. D. Huntley, \& N. T. Neill (Eds.), Teaching and learning mathematical modelling: Innovation, investigation and applications (pp.51-61). England: Albion Publishing Limited.

Jurow, A. S. (2004). Generalizing in interaction: middle school mathematics students making mathematical generalizations in a population-modeling project. Mind, Culture, and Activity, 11(4), 279-300. http://dx.doi.org/10.1207/s15327884mca1104_4

Kaiser, G., \& Stender, P. (2013). Complex modelling problems in co-operative, self-directed learning environments. In G. Stillman, G. Kaiser, W. Blum, \& J. Brown (Eds.), Teaching mathematical modelling: Connecting to research and practice (pp.275-293). New York: Springer. http://dx.doi.org/10.1007/978-94-007-6540-5_23

Kaiser, G., Schwarz, B., \& Buchholtz, N. (2011). Authentic modelling problems in mathematics education. In G. Kaiser, W. Blum, R. Borromeo Ferri, \& G. Stillman (Eds.), Trends in teaching and learning of mathematical modelling. (pp.591-601). New York: Springer. http://dx.doi.org/10.1007/978-94-007-0910-2_57

Kaiser, G. (2011). Introduction to the papers of WG 6: Applications and modelling. In M. Pytlak, T. Rowland, \& E. Swoboda (Eds.), Proceedings of the Seventh Congress of the European Society for Research in Mathematics Education. (pp. 925-926). Rzeszow, Poland: European Society for Research in Mathematics Education.

Kaiser, G., \& MaaB, K. (2007). Modelling in lower secondary mathematics classroom-problems and opportunities. In W. Blum, P. Galbraith, H. Henn, \& M. Niss, (Eds.), Modelling and applications in mathematics education (pp.99-108). New York: Springer. http://dx.doi.org/10.1007/978-0-387-29822-1_8

Kaiser, G., \& Sririman, B. (2006). A global survey of international perspectives on modelling in mathematics education. ZDM, 38(3), 302-310. http://dx.doi.org/10.1007/BF02652813

Kaiser, G., \& Schwarz, B. (2006). Mathematical modelling as bridge between school and university. ZDM, 38 (2), 196-208. http://dx.doi.org/10.1007/BF02655889

Lege, J. (2007). "To model, or to let them model?" That is the Question! In W. Blum, P. Galbraith, H. Henn, \& M. Niss (Eds.), Modelling and applications in mathematics education (pp.425-432). New York: Springer. http://dx.doi.org/10.1007/978-0-387-29822-1_47

Lesh, R. (2010). Tools, researchable issues \& conjectures for investigating what it means to understand statistics (or other topics) meaningfully. Journal of Mathematical Modelling and Application, 1(2), 16-48.

Lesh, R., Carmona, G., \& Moore, T. (2009). Six sigma learning gains and long term retention of understandings and attitudes related to models \& modeling. Mediterranean Journal for Research in Mathematics education, 9(1), 19-54.

Lesh, R., \& Carmona, G. (2003). Piagetian conceptual systems and models for mathematizing everyday experiences. In R. Lesh \& H. Doerr (Eds.), Beyond constructivism: Models and modeling perspectives on mathematics problem solving, teaching, and learning (pp.71-96). New York: Routledge.

Lesh, R., \& Doerr, H. M. (2003a) Foundations of a models and modeling perspective on mathematics teaching, learning, and problem solving. In R. Lesh, \& H. Doerr (Eds.), Beyond constructivism (pp.3-38). Mahwah, NJ: Lawrence Erlbaum Associates.

Lesh, R., \& Doerr, H. M. (2003b) In what ways does a models and modeling perspective move beyond constructivism? In R. Lesh \& H. Doerr (Eds.), Beyond constructivism (pp.519-556). Mahwah, NJ: Lawrence Erlbaum Associates.

Lesh, R., \& Harel, G. (2003). Problem solving, modeling, and local conceptual development. Mathematical Thinking and Learning, 5(2\&3), 157-189. http://dx.doi.org/10.1080/10986065.2003.9679998

Lesh, R., Hoover, M., Hole, B., Kelly, A. and Post, T. (2000). Principles for developing thought-revealing activities for students and teachers, in A. Kelly \& R. Lesh (Eds.), Research design in mathematics and science education 
(pp.591-646). Mahwah, NJ: Lawrence Erlbaum and Associates.

Lesh, R., \& Kelly, A. E. (2000). Multi-tiered teaching experiments. In R. A. Lesh \& A. Kelly (Eds.), Handbook of research design in mathematics and science education (pp.197-230). Mahwah: Lawrence Erlbaum.

Lesh, R., \& Kaput, J. (1988). Interpreting modeling as local conceptual development. In J. DeLange \& M. Doorman (Eds.), Senior secondary mathematics education. Utrecht, The Netherlands: OW \& OC.

Lingefjard, T., \& Meier, S. (2011). The sun hour project. In G. Kaiser, W. Blum, R. Borromeo Ferri, \& G. Stillman (Eds.), Trends in teaching and learning of mathematical modelling. (pp.97-106). New York: Springer. http://dx.doi.org/10.1007/978-94-007-0910-2_11

Ludwig, M., \& Reit, X. (2013). A cross-sectional study about modelling competency in secondary school. In G. Stillman, G. Kaiser, W. Blum, \& J. Brown (Eds.), Teaching mathematical modelling: Connecting to research and practice (pp.327-337). New York: Springer. http://dx.doi.org/10.1007/978-94-007-6540-5_27

Ludwig, M., \& Xu, B. (2008). A comparative study of modelling competencies among Chinese and German students. In M. Blomhoj \& S. Carreira (Eds.), Mathematical applications and modelling in the teaching and learning of mathematics: Proceedings from TSG 21 at ICME 11 (pp.197-206). Roskilde: IMFUFA, Roskilde University.

MaaB, K., \& Mischo, C. (2011). Implementing modelling into day-to-day teaching practice-The project STRATUM and its framework. Journal fur Mathematik-Didaktik, 32, 103-131. http://dx.doi.org/10.1007/s13138-010-0015-X

MaaB, K. (2007). Modelling in class: what do we want the students to learn? In C. Haines, P. Galbraith, W. Blum, \& S. Khan, S (Eds.), Mathematical modelling: Education, engineering and economics (pp.63-78). Chichester, England: Horwood Publishing.

MaaB, K. (2006). What are modelling competencies? ZDM, 38(2), 113-142. http://dx.doi.org/10.1007/BF02655885

MaaB, K. (2010). Modeling in class and the development of beliefs about the usefulness of Mathematics. In R. Lesh, P. Galbraith, C. Haines, \& A. Hurford (Eds.), Modeling students' mathematical modeling competencies (pp.409-420). New York: Springer.

Matsuzaki, A. (2007). How might we share models through cooperative mathematical modelling? Focus on situations based on individual experiences. In W. Blum, P. Galbraith, H. Henn, \& M. Niss (Eds.), Modelling and applications in mathematics education (pp.357-364). New York: Springer. http://dx.doi.org/10.1007/978-0-387-29822-1_38

McClain, K. (2003). Task-analysis cycles as tools for supporting students' mathematical development. In R. Lesh \& H. Doerr (Eds.), Beyond constructivism: Models and modeling perspectives on mathematics problem solving, teaching, and learning (pp.175-190). New York: Routledge.

Mousoulides, N., \& English, L. D. (2011). Engineering model eliciting activities for elementary school students. In G. Kaiser, W. Blum, R. Borromeo Ferri, \& G. Stillman, (Eds.), Trends in teaching and learning of mathematical modelling. (pp.221-230). New York: Springer. http://dx.doi.org/10.1007/978-94-007-0910-2_23

Mousoulides, N., Pittalis, M., Christou, C., \& Sriraman, B. (2010). Tracing students' modeling processes in school. In R. Lesh, P. Galbraith, C. Haines, \& A. Hurford (Eds.), Modeling students' mathematical modeling competencies (pp.119-129). New York: Springer. http://dx.doi.org/10.1007/978-1-4419-0561-1_10

Mousoulides, N., Christou, C., \& Sriraman, B. (2008). A modeling perspective on the teaching and learning of mathematical problem solving. Mathematical Thinking and Learning, 10, $293-304$. http://dx.doi.org/10.1080/10986060802218132

Mousoulides, N., Sriraman, B., Pittalis, M., \& Christou, C. (2007). Tracing students' modelling processes in elementary and secondary school. In D. Pitta. \& G. Philippou (Eds.), Proceedings of the fifth Congress of the European Society for Research in Mathematics Education. (pp. 2130-2139). Larnaca, Cyprus: European Society for Research in Mathematics Education.

National Academy of Engineering (2009). Engineering in K-12 education: Understanding the status and improving the prospects. Washington, DC: National Academies Press.

Ng, K.E.D. (2011). Mathematical knowledge application and student difficulties in a design-based interdisciplinary project. In G. Kaiser, W. Blum, R. Borromeo Ferri, \& G. Stillman (Eds.), Trends in teaching and learning of mathematical modelling. (pp.107-116). New York: Springer. http://dx.doi.org/10.1007/978-94-007-0910-2_12

Pajares, M. (1992). Teachers' beliefs and educational research: Cleaning up a messy construct. Review of Educational Research, 62, 307-332. http://dx.doi.org/10.3102/00346543062003307

Park, J., Park, M. S., Park, M., Cho, J., \& Lee, K. H. (2013). Mathematical modelling as a facilitator to 
conceptualization of the derivative and the integral in a spreadsheet environment. Teaching Mathematics and Its Applications, 32, 123-139. http://dx.doi.org/10.1093/teamat/hrt012

Perrenet, J., \& Zwaneveld, B. (2012). The many faces of the mathematical modeling cycle. Journal of Mathematical Modelling and Application, 1(6), 3-21.

Piaget, J., Inhelder, B., \& Szeminska, A. (1960). The child's conception of geometry. London: Butler and Tanner.

Schukajlow, S., Leiss, D., Pekrun, R., Blum, W., Muller, M., \& Messner, R. (2011). Teaching methods for modelling problems and students' task-specific enjoyment, value, interest, and self-efficacy expectations. Educational Studies in Mathematics, 79, 215-237. http://dx.doi.org/10.1007/s10649-011-9341-2

Sfard, A. (2008). Thinking as communicating: Human development, the growth of discourses, and mathematizing. Cambridge: Cambridge University Press. http://dx.doi.org/10.1017/CBO9780511499944

Skovsmose, O. (1994). Towards a critical mathematics education. Educational Studies in Mathematics, 27(1), 35-57. http://dx.doi.org/10.1007/BF01284527

Sol, M., Gimenez, J., Rosich, N. (2011). Project modelling routes in 12-16-year-old pupils. In G. Kaiser, W. Blum, R. Borromeo Ferri, \& G. Stillman (Eds.), Trends in teaching and learning of mathematical modelling. (pp.231-240). New York: Springer.

Stillman, G., Brown, J. P., \& Galbraith, P. (2013). Challenges in modelling challenges: intents and purposes. In G. Stillman, G. Kaiser, W. Blum, \& J. Brown (Eds.), Teaching mathematical modelling: Connecting to research and practice (pp.217-227). New York: Springer. http://dx.doi.org/10.1007/978-94-007-6540-5_19

Stillman, G. (2011). Applying metacognitive knowledge and strategies in applications and modelling tasks at secondary school. In G. Kaiser, W. Blum, R. Borromeo Ferri, \& G. Stillman (Eds.), Trends in teaching and learning of mathematical modelling. (pp.165-180). New York: Springer. http://dx.doi.org/10.1007/978-94-007-0910-2_18

Stillman, G., Brown, J., \& Galbraith, P. (2010). Identifying challenges within transition phases of mathematical modeling activities at year 9. In R. Lesh, P. Galbraith, C. Haines, \& A. Hurford (Eds.), Modeling students' mathematical modeling competencies (pp.385-398). New York: Springer. http://dx.doi.org/10.1007/978-1-4419-0561-1_33

Stillman, G. (2000). Impact of prior knowledge of task context on approaches to applications tasks. Journal of Mathematical Behavior, 19(1), 333-361. http://dx.doi.org/10.1016/S0732-3123(00)00049-3

Stohlmann, M., \& Albarracin, L. (2016). What is known about elementary grades mathematical modelling. Education Research International, 2016, 1-9. http://dx.doi.org/10.1155/2016/5240683

Stohlmann, M. (2013). Model-Eliciting Activities: Fostering $21^{\text {st }}$ century learners. Journal of Mathematics Education at Teachers College, 4(2), 60-65.

Yanagimoto, A., \& Yoshimura, N. (2013). Mathematical Modelling of a real-world problem: The decreasing number of Bluefin tuna. In G. Stillman, G. Kaiser, W. Blum, \& J. Brown (Eds.), Teaching mathematical modelling: Connecting to research and practice (pp.229-239). New York: Springer. http://dx.doi.org/10.1007/978-94-007-6540-5_20 


\section{Appendix}

Publications categorized by source

\begin{tabular}{l}
\hline Journal or conference \\
\hline International Community of Teachers \\
of Mathematical Modelling and \\
Applications (ICTMA) edited book \\
chapters
\end{tabular}

Congresses of the European Society for Research in Mathematics Education (CERME) proceedings

Book: Beyond Constructivism: Foundations of a models and modeling perspective on mathematics teaching, learning, and problem solving ZDM

Educational Studies in Mathematics

International Commission on Mathematical Instruction (ICMI) 14 study on modeling and applications in mathematics education

Mathematical Thinking and Learning

Journal for Research in Mathematics Education

Teaching Mathematics and its Applications

Journal of Mathematical Modelling and Application

Journal of Mathematics Education at Teachers College

The Montana Mathematics Enthusiast

Journal fur Mathematik-Didaktik

Mind, Culture, and Activity

\section{Publications}

Abrantes, 1993; Andresen \& Petersen, 2011; Arleback \& Frejd, 2013; Arleback \& Bergsten, 2010; Biccard \& Wessels, 2011; Blum \& LeiB, 2007; Bracke \& Geiger, 2011; Brown, 2013; Brown \& Edwards, 2011; Busse, 2011; Busse \& Kaiser, 2003; Carmona, 2003; Cheng, 2013; Dunne \& Galbraith, 2003; English, 2013; Eric, 2013; Galbraith, Stillman, Brown, \& Edwards, 2007; Greefrath, 2010; Grigoras, Garcia, \& Halverscheid, 2011; Grunewald, 2013; Ikeda, 1997; Kaiser \& Stender, 2013; Kaiser, Schwarz, \& Buchholtz, 2011; Lingefjard \& Meier, 2011; Ludwig \& Reit, 2013; MaaB, 2007; Maass, 2010; Mousoulides \& English, 2011; Mousoulides, Pittalis, Christou, \& Sriraman, 2010; Ng, 2011; Sol, Gimenez, \& Rosich, 2011; Stillman, Brown, \& Galbraith, 2013; Stillman, 2011; Stillman, Brown \& Galbraith, 2010; Yanagimoto \& Yoshimura, 2013.

Albarracin \& Gorgorio, 2013; Arleback, 2011; Carreira \& Baioa, 2015; Djepaxhija, Vos, \& Fuglestad, 2015; Doerr \& Arleback, 2015; Hamacher \& KreuBler, 2013; Mousoulides, Sriraman, Pittalis, \& Christou, 2007.

Aliprantis \& Carmona, 2003; Harel \& Lesh, 2003; Lesh \& Carmona, 2003; Lesh \& Doerr, 2003a; McClain, 2003;

Barbosa, 2006; Galbraith \& Stillman, 2006; Kaiser \& Schwarz, 2006; MaaB, 2006.

Galbraith \& Clatworthy, 1990; Hitt \& Gonzalez-Martin, 2015; Schukajlow, Leiss, Pekrun, Blum, Muller, \& Messner, 2011; Skovsmose, 1994.

Kaiser \& Maab, 2007; Matsuzaki, 2007; Lege, 2007.

Arleback, Doerr, \& O’Neil, 2013; Lesh \& Harel, 2003; Mousoulides, Christou, \& Sriraman, 2008.

Doerr \& English, 2003.

Park, Park, Park, Cho, \& Lee, 2013

Ikeda \& Stephens, 2010

Gould \& Wasserman, 2014

Arleback, 2009

MaaB \& Mischo, 2011

Jurow, 2004

\section{Copyrights}

Copyright for this article is retained by the author(s), with first publication rights granted to the journal.

This is an open-access article distributed under the terms and conditions of the Creative Commons Attribution license (http://creativecommons.org/licenses/by/4.0/). 